\title{
Triboelectric Hydrogen Gas Sensor with Pd Functionalized Surface
}

\author{
Sung-Ho Shin ${ }^{1}$, Yang Hyeog Kwon ${ }^{1}$, Young-Hwan Kim ${ }^{1}$, Joo-Yun Jung ${ }^{2, *}$ and Junghyo Nah ${ }^{1, *}$ \\ 1 Department of Electrical Engineering, Chungnam National University, Daejeon 34134, Korea; \\ shinsh@cnu.ac.kr (S.-H.S.); yhkwon@cnu.ac.kr (Y.H.K.); kyhwan@cnu.ac.kr (Y.-H.K.) \\ 2 Department of Nano Manufacturing Technology, Korea Institute of Machinery and Materials, \\ Daejeon 34103, Korea \\ * Correspondence: jjy2121@kimm.re.kr (J.-Y.J.); jnah@cnu.ac.kr (J.N.); Tel.: +82-42-821-5655 (J.N.) \\ Academic Editor: Chen-Zhong Li \\ Received: 9 August 2016; Accepted: 8 October 2016; Published: 14 October 2016
}

\begin{abstract}
Palladium (Pd)-based hydrogen $\left(\mathrm{H}_{2}\right)$ gas sensors have been widely investigated thanks to its fast reaction and high sensitivity to hydrogen. Various sensing mechanisms have been adopted for $\mathrm{H}_{2}$ gas sensors; however, all the sensors must be powered through an external battery. We report here an $\mathrm{H}_{2}$ gas sensor that can detect $\mathrm{H}_{2}$ by measuring the output voltages generated during contact electrification between two friction surfaces. When the $\mathrm{H}_{2}$ sensor, composed of Pd-coated ITO (indium tin oxide) and PET (polyethylene Terephthalate) film, is exposed to $\mathrm{H}_{2}$, its output voltage is varied in proportion to $\mathrm{H}_{2}$ concentration because the work function (WF) of Pd-coated surface changes, altering triboelectric charging behavior. Specifically, the output voltage of the sensor is gradually increased as exposing $\mathrm{H}_{2}$ concentration increases. Reproducible and sensitive sensor response was observed up $1 \% \mathrm{H}_{2}$ exposure. The approach introduced here can easily be adopted to development of triboelectric gas sensors detecting other gas species.
\end{abstract}

Keywords: self-powered sensor; $\mathrm{H}_{2}$ detection; palladium; gas sensor; triboelectricity

\section{Introduction}

Hydrogen $\left(\mathrm{H}_{2}\right)$ has been claimed to be an alternative to replace fossil fuels [1-4]. Since $\mathrm{H}_{2}$ is flammable, explosive, colorless, and odorless gas, precise detection of its concentration is important for prevention of potential accidents and its safe use [5]. Thus, many $\mathrm{H}_{2}$ sensors, exploiting different sensing mechanisms, have been introduced to date [6-9]. Among them, palladium (Pd)-based $\mathrm{H}_{2}$ sensor is one of the most widely used $\mathrm{H}_{2}$ sensors due to its fast reaction to $\mathrm{H}_{2}$, high sensitivity, and selectivity [10-19]. When $\mathrm{Pd}$ is exposed to $\mathrm{H}_{2}$ molecules, $\mathrm{Pd}$ is reacted with $\mathrm{H}_{2}$ by absorbing $\mathrm{H}_{2}$ molecules inside its lattice, expanding the volume: $\mathrm{Pd}$ is transformed as either $\alpha$-phase $\mathrm{PdH}_{x}$ or $\beta$-phase $\mathrm{PdH}_{x}$ depending on exposed $\mathrm{H}_{2}$ concentrations. Consequently, the electrical and optical properties of $\mathrm{Pd}$ are changed as it is exposed to $\mathrm{H}_{2}$. Using this mechanism, several $\mathrm{H}_{2}$ sensors have been reported. For instance, $\mathrm{H}_{2}$ sensors, utilizing nanogap structures $[10,11]$, surface acoustic wave (SAW) $[13,14]$, Schottky diodes structure [15,16], and surface plasmon effect $[17,18]$, have been reported. Recently, triboelectric energy harvesting has gained much attention as a route to supply necessary power to operate electronic devices [20-26]. Further, few attempts have been made to develop chemical sensors utilizing triboelectric effect $[27,28]$. Specifically, detection is usually made by measuring variable triboelectric output as a result of friction surface reaction with target gas molecules [27]. However, only limited chemical species have been probed so far and further investigation is necessary to expand its application.

Here, we report a self-powered $\mathrm{H}_{2}$ gas sensor by adopting triboelectric effects. When two dielectric surfaces on metal electrode are periodically contacted and released, each surface is electrified due 
to charge separation between two surfaces. The surface that gained electrons is charged negatively, while the other surface that lost electrons is positively charged, depending on their difference in electron affinity. These surface charges electrostatically induce counter charges on the facing metal electrode, developing the potential difference between two metal electrodes. Therefore, when the two electrodes are connected through an external load, it drives the electrons to flow between them. In this work, based on this triboelectric generation mechanism, we report a self-powered $\mathrm{H}_{2}$ gas sensor, demonstrating reliable sensing performance from $0 \%$ to $1 \% \mathrm{H}_{2}$ exposures.

\section{Results and Discussion}

\subsection{Preperation of Self-Powered $\mathrm{H}_{2}$ Gas Sensor}

The schematic representation of the self-powered $\mathrm{Pd} \mathrm{H}_{2}$ gas sensor is shown in Figure 1a. Two indium tin oxide (ITO) $(130 \mathrm{~nm}) /$ polyethylene Terephthalate (PET) $(130 \mu \mathrm{m})$ substrates (dimension: $1 \mathrm{~cm} \times 1 \mathrm{~cm} \times 130.13 \mu \mathrm{m}$ ) are first cleaned with IPA acetone and DI water, respectively. On one substrate, a $10 \mathrm{~nm}$-thick Pd is thermally evaporated on the ITO side of the substrate as an active $\mathrm{H}_{2}$ sensing layer. The other substrate is used as the contacting substrate without any chemical treatment or coating, where the PET side of the substrate is employed as a counter contact surface. Lastly, ITO electrodes of the two substrates are connected through an external circuit. Figure $1 \mathrm{~b}$ shows the cross sectional transmission electron microscopy (TEM) of the evaporated Pd. The Pd layer id co-deposited on a $\mathrm{Si} / \mathrm{SiO}_{2}$ substrate in order to measure the thickness of the Pd layer. It can be noticed that $\sim 10 \mathrm{~nm}$ evaporated $\mathrm{Pd}$ is deposited on the substrate. Next, energy-dispersive $\mathrm{X}$-ray spectroscopy (EDS) was also examined to verify the evaporated Pd layer on the ITO surface (Figure 1c).

(a)
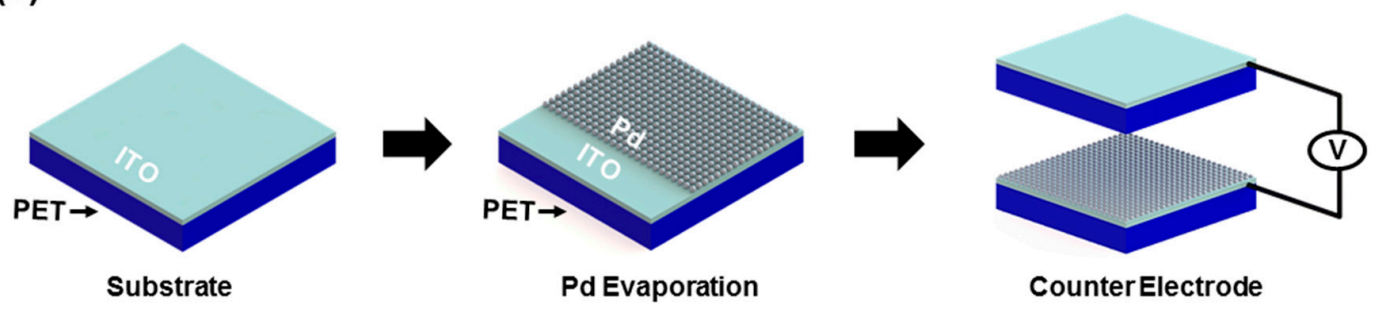

(b)

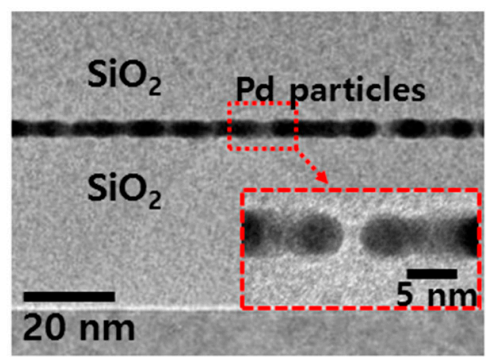

(c)

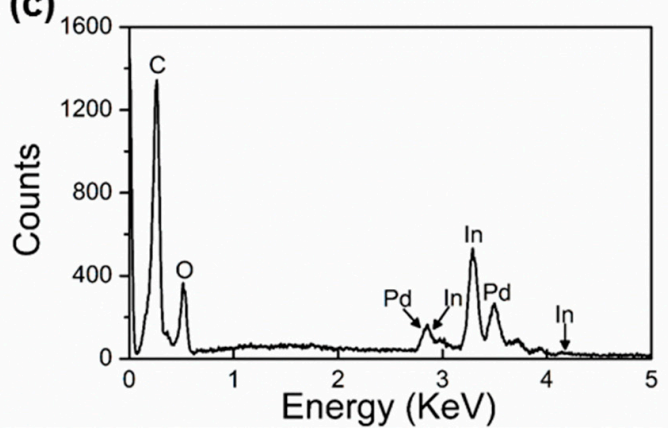

Figure 1. (a) Schematic representations of self-powered $\mathrm{H}_{2}$ gas sensor fabrication. First, a 10 nm-thick $\mathrm{Pd}$ is thermally evaporated on an indium tin oxide (ITO) surface. The courter surface consists of the polyethylene Terephthalate (PET) and ITO layer. Two contacting surfaces, PET and ITO surfaces, were periodically pressed and released during measurement. Triboelectric output voltages were measured while exposing the devices at different concentrations of $\mathrm{H}_{2}$ gas; (b) transmission electron microscopy (TEM) shows the thickness of evaporated Pd layer, $\sim 10 \mathrm{~nm}$; (c) energy-dispersive X-ray spectroscopy (EDS) of Pd coated ITO electrode. It clearly indicates the contents of Pd deposited on an ITO/PET substrate. 


\subsection{Self-Powered $\mathrm{H}_{2}$ Gas Sensor Test Set up}

For self-powered $\mathrm{H}_{2}$ gas sensor measurement, the test setup shown in Figure 2 was prepared. The test setup is composed of two parts: gas flow control unit, exposing gas concentration using mass flow control units (MFCs) by introducing $5 \% \mathrm{H}_{2}$ and dry air at specific ratios, and measurement unit, measuring voltage between two electrodes by periodic contact. Experimental details of gas exposure are described in the Materials and Methods section. A specific concentration of $\mathrm{H}_{2}$, prepared in the gas control part, flowed into an enclosed gas chamber (length $\times$ width $\times$ height: $6 \mathrm{~cm} \times 6 \mathrm{~cm} \times 6 \mathrm{~cm}$ ), within which the custom-built pushing machine is installed. Two surfaces of the $\mathrm{H}_{2}$ sensor were mounted on the pushing machine and were contacted periodically during pressing and releasing motions.

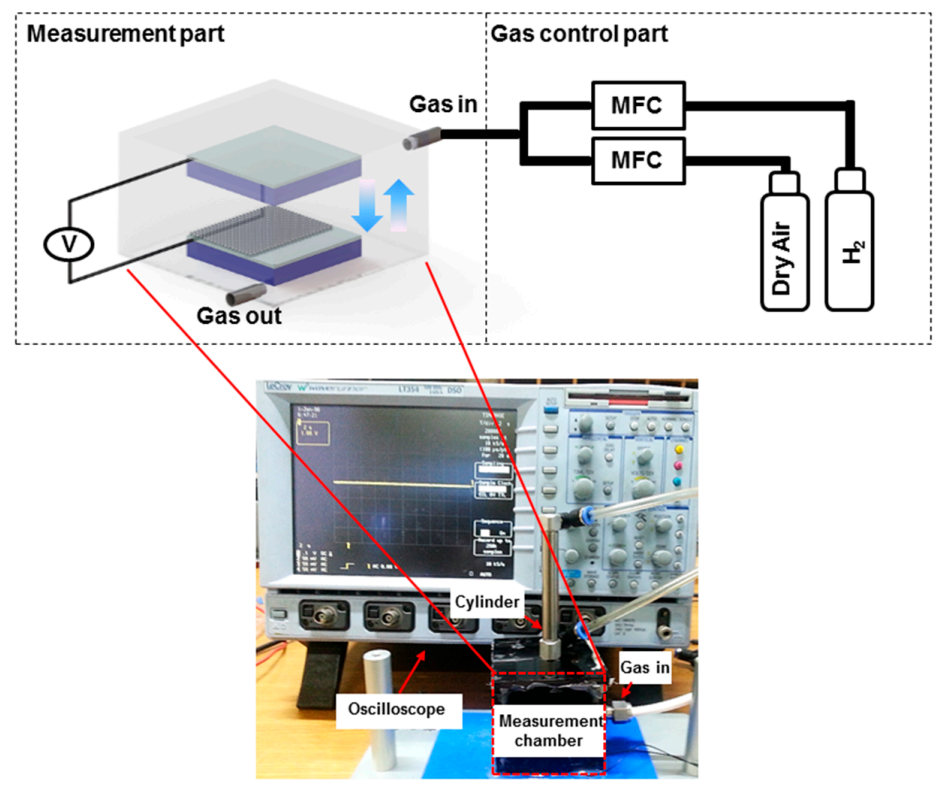

Figure 2. $\mathrm{H}_{2}$ gas sensor test setup consisting of gas control part and measurement part. A specific concentration of $\mathrm{H}_{2}$ is precisely controlled by mixing dry air and $\mathrm{H}_{2}$ at different ratio and the mixed gas is then introduced into the measurement chamber with a custom-made pushing machine installed inside. The output signals from the sensor were measured using the data acquisition instrument.

\subsection{Mechanism and Output Performance of Self-Powered $\mathrm{H}_{2}$ Gas Sensor}

Figure 3a shows the sensing mechanism of a self-powered $\mathrm{H}_{2}$ gas sensor, driven by triboelectric induction mechanism [29]. At the initial state, both Pd and PET surfaces have no surface charges. As the two surfaces are compressed, the electrons from donor interface states of the PET surface move toward Pd-functionalized ITO electrode through an external circuit, negatively charging the Pd-functionalized surface and positively charging the PET surface (Figure 3(ai)) [20]. As the two surfaces start to become separated, the surface charges on both contacting surfaces induce counter charges on the facing electrodes, developing the potential difference between the top and bottom electrode (Figure 3(aii)). At the fully separated state, charge equilibrium state is reached between the contacting surfaces and facing electrodes (Figure 3(aiii)). Lastly, as the two surfaces make contact again, induced charges on the electrodes disappear again due to a break of the charge neutral state (Figure 3(aiv)). To demonstrate the roles of Pd-functionalization, output voltages of the sensor without Pd-functionalized surface were first investigated (Figure 3b). When the non Pd-functionalized ITO and PET surfaces are contacted, it exhibits constant output voltage for varying $\mathrm{H}_{2}$ gas concentration from $0 \%$ to $5 \%$. Since both PET and ITO do not react with $\mathrm{H}_{2}$ molecules, the output voltage signals were solely determined by the initial triboelectric sequence difference between them. Next, the output signals between Pd-functionalized ITO surface and PET were examined as a function of different exposing $\mathrm{H}_{2}$ 
concentrations. Differently from the non-functionalized device, it can be clearly noticed that the output voltages of the sensor are increased in proportion to $\mathrm{H}_{2}$ exposure (Figure 3c). The sensor output is more linearly increased up to $1 \% \mathrm{H}_{2}$ exposure. However, the sensor response is rather saturated when the $\mathrm{H}_{2}$ concentration exceeds $2 \%$. The observed behavior is consistent with other Pd-based hydrogen gas sensor $[11,14]$. Thus, Pd-functionalization plays a key role in triboelectric $\mathrm{H}_{2}$ detection. In Figure $3 \mathrm{~d}$, the energy band structure of the sensor is drawn to explain the increase of triboelectric output voltage with exposure to $\mathrm{H}_{2}$. The work function (WF) of $\mathrm{Pd}$ is $\sim 5.2 \mathrm{eV}$ and thus its Fermi level is located slightly above the midgap of PET [30]. As a result, when the two surfaces are contacted, carriers in valence and conduction bands of PET cannot be responsible for observed triboelectric charge exchange between the two surfaces. Therefore, the surface states must play an important role in contact electrifications between the two materials. Here, when the Pd-coated ITO surface is contact-electrified against the PET surface, Pd is negatively charged while PET is positively charged. This indicates that there must be donor states ( 0.55 and $0.85 \mathrm{eV}$ below conduction band) near the midgap of PET, located slightly above the Fermi level of Pd [31]. As Pd is being exposed to $\mathrm{H}_{2}, \mathrm{H}_{2}$ molecules are dissociated and absorbed in the Pd lattice, forming $\mathrm{PdH}_{x}$ (palladium hydride). When $\mathrm{PdH}_{x}$ is formed, its WF becomes smaller than that of Pd [32]. Consequently, as the WF of $\mathrm{PdH}_{x}$ moves more close to donor states in PET, the charge exchange between two materials can be more effective, which enhances surface charge exchange and leads to increase in triboelectric output voltage of the sensor. Therefore, triboelectric output voltage will be continuously increased until $\mathrm{H}_{2}$ concentration reaches a certain level.

(a)

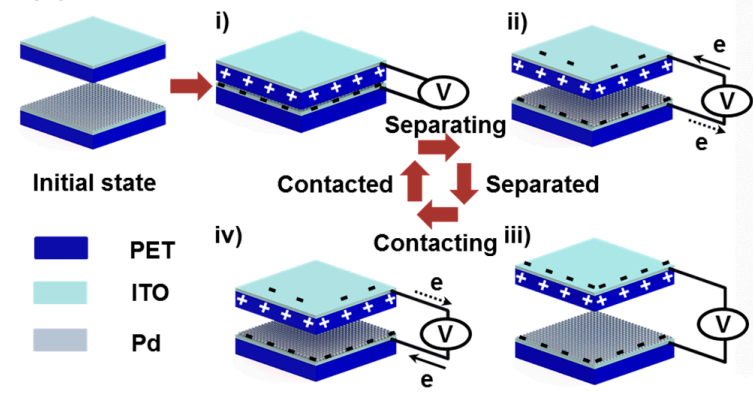

(c)

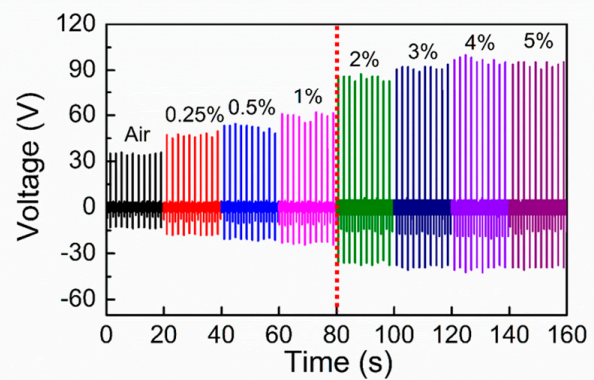

(b)

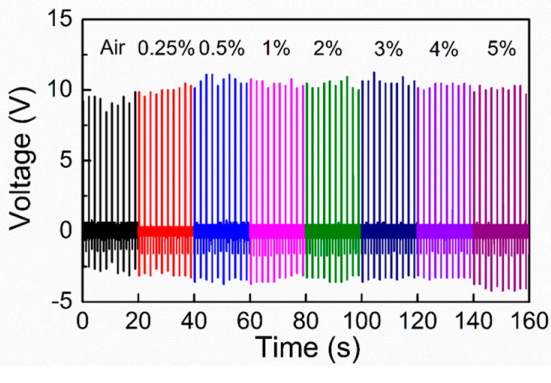

(d)

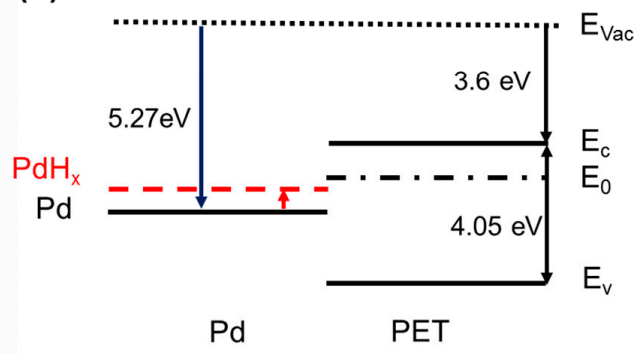

Figure 3. (a) Triboelectric generation mechanism. (initial state) There is no charge on both surfaces. (i) contacted state: charge separation between the two surfaces by contact electrification; (ii) releasing state: differently charged contact surface induces charge flows between the top and bottom electrodes; (iii) separated state: charge neutral state is reached; (iv) pressing state: electrical equilibrium state breaks again and induced charges flow in opposite direction; (b) Triboelectric output voltages from non Pd-functionalized ITO and PET contact pair. There is no output voltage change since Pd does not react with $\mathrm{H}_{2}$ gas; (c) Triboelectric output voltage of the $\mathrm{H}_{2}$ gas sensor with a Pd-functionalized ITO and PET contact pair in varying $\mathrm{H}_{2}$ concentrations. The output voltage sublinearly increases until $\mathrm{H}_{2}$ concentration reaches $1 \%$. The output voltages are saturated above $3 \% \mathrm{H}_{2}$ concentration; (d) Energy band diagrams of contact surfaces. Work function (WF) of Pd moves close to donor surface states $\left(\mathrm{E}_{0}\right)$ of PET as $\mathrm{PdH}_{x}$ is formed, increasing surface charge exchange. 
To verify reproducible output performance of the $\mathrm{H}_{2}$ sensor, the device was measured while repeatedly being exposed to different concentrations of $\mathrm{H}_{2}$ (up to $1 \% \mathrm{H}_{2}$ ) (Figure 4a). Similar output voltages were measured during the repeated measurement. The magnified output signals in Figure 4a show alternating peaks due to the triboelectric induction mechanism described in Figure 3a. Next, sensor response and recovery time were measured while exposing under $1 \%$ hydrogen, exhibiting the response and recovery time of $\sim 30 \mathrm{~min}$ and $\sim 15 \mathrm{~min}$, respectively (Figure $3 \mathrm{~b}$ ). In addition, the effect of relative humidity (RH) on the sensor output was also measured. It can be noticed that the output voltage is obviously reduced when the $\mathrm{RH}$ is increased from $47 \%$ to $65 \%$, negatively affecting triboelectric output voltage. Lastly, the sensor responses were calculated from multiple devices and plotted as a function of exposing $\mathrm{H}_{2}$ concentrations (Figure $4 \mathrm{~d}$ ). Here, the sensor responses were calculated using the equation $\Delta V / V_{0}$, where $V_{0}$ is the output voltage measured while being exposed to dry air, $V_{S}$ is the output voltage under exposure to a specific $\mathrm{H}_{2}$ concentration, and $\Delta V\left(=V_{S}-V_{0}\right)$ is a relative output voltage change between two states. A gradual increase of sensor response can be noticed as $\mathrm{H}_{2}$ concentration increases. We also note that the sensor response was more widely varied when the $\mathrm{H}_{2}$ concentration exceeds $2 \%$. Using the obtained sensor responses, the sensitivity of the hydrogen sensor is subsequently extracted, where the sensitivity is calculated using the equation, $S=\frac{d\left(\mathrm{~V} / \mathrm{V}_{0}\right)}{d\left(\left[\mathrm{H}_{2}\right)\right)}$. Up to $1 \% \mathrm{H}_{2}$ exposures, higher sensitivity, 0.75 , was obtained. Above $2 \% \mathrm{H}_{2}$ exposures, on the other hand, the sensitivity is reduced to 0.2 , indicating the saturation of $\mathrm{H}_{2}$ molecules absorption in Pd lattice above this level.

(a)

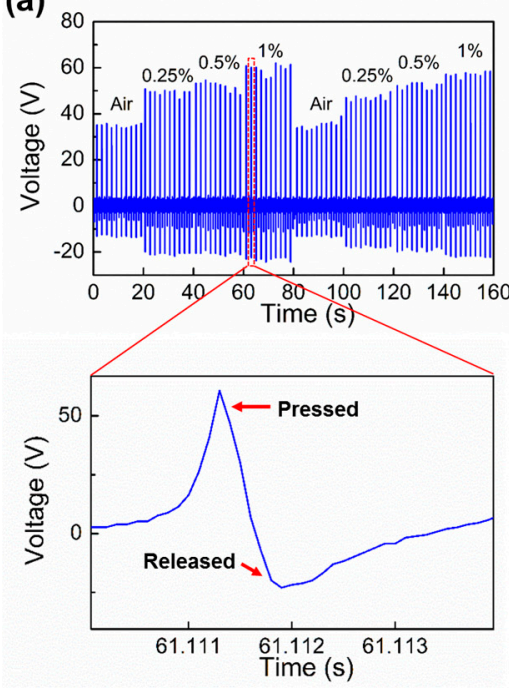

(b)

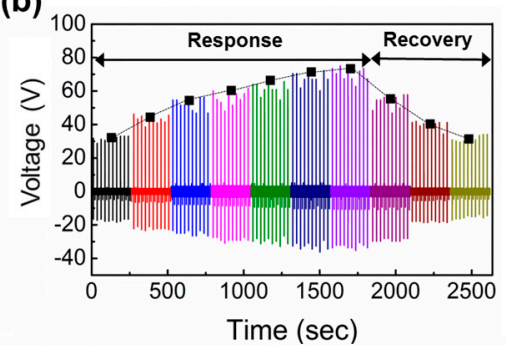

(d)

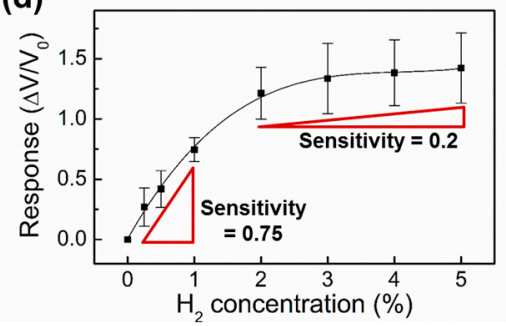

(c)

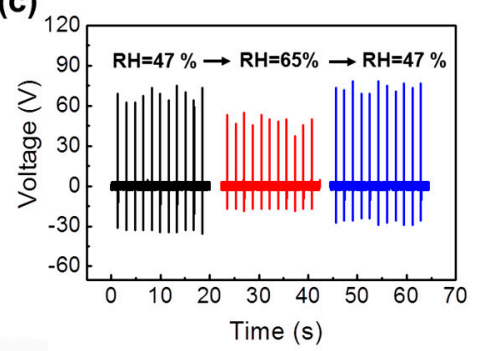

Figure 4. (a) Reproducible sensor responses. Similar outputs are repeatedly measured when the sensor is repeatedly exposed to $\mathrm{H}_{2}$; (b) Sensor response and recovery time under $1 \%$ hydrogen exposure; (c) Humidity effect on sensor output performance; (d) Sensor responses $\left(\Delta V / V_{0}\right)$ under exposure to different concentrations of $\mathrm{H}_{2}$.

\section{Materials and Methods}

\subsection{Measurement and Characterization}

Triboelectric output voltages were measured while exposing the device in different $\mathrm{H}_{2}$ gas concentrations. We maintained total flux of dry air and $\mathrm{H}_{2}$ as $200 \mathrm{sccm}$. For each $\mathrm{H}_{2}$ concentration, the sample was exposed to each $\mathrm{H}_{2}$ concentration for $30 \mathrm{~min}$, which is sufficient reaction time for $\mathrm{Pd}$ in the presence of $\mathrm{H}_{2}$ gas. Different concentrations of $\mathrm{H}_{2}$ were introduced into the chamber by mixing with dry air at the specific ratios using mass flow control (MFC) units. For all measurement, a constant force of $0.1 \mathrm{MPa}$ was applied using the custom-made pushing machine installed inside of a gas chamber at a frequency of $0.5 \mathrm{~Hz}$ and the distance between two electrodes was kept as $3.5 \mathrm{~cm}$. 
The output voltages from the sensor were measured by connecting to the oscilloscope (Waverunner 2 LT 354, Lecroy, Chestnut Ridge, NY, USA). The Pd-coated layer was characterized by using both TEM (JEM-ARM200F, JEOL, Tokyo, Japan) and EDS (HD-2300A, Hitachi, Tokyo, Japan) before gas sensing measurement.

\subsection{Fabrication of Triboelectric $\mathrm{H}_{2}$ Gas Sensor}

For fabrication of triboelectric $\mathrm{H}_{2}$ gas sensors, the surface of ITO $(130 \mathrm{~nm})$-coated PET $(130 \mu \mathrm{m})$ film (Sigma Aldrich, Darmstadt, Germany) was first cleaned with IPA, acetone, and DI water, respectively, followed by $\mathrm{N}_{2}$ blow dry. After cleaning the film, Pd $(10 \mathrm{~nm})$ was thermally evaporated on an ITO surface of the film. Next, the counter contact surface, consisting of PET/ITO film, was prepared. Here, Pd-coated ITO surface was contact-electrified with the PET side of the counter contact surface. Electrical connection between ITO electrodes of the two friction surfaces was made using copper wires. For electrical connection of the ITO surface and copper line as an electrode, the electrode was soldered by soldering with silver paste. Each prepared surface was then mounted on the custom-made pushing machine installed inside a gas test chamber.

\section{Conclusions}

In summary, we demonstrated self-powered $\mathrm{H}_{2}$ gas sensor utilizing triboelectric effects. Due to WF change of Pd-coated surface in the presence of $\mathrm{H}_{2}$, triboelectric output voltage of the sensor was varied proportionally. Using this mechanism, different concentrations of $\mathrm{H}_{2}$ were detected during contact electrification between two friction surfaces without using an external battery. Specifically, the output voltage of $\mathrm{H}_{2}$ sensor was increased in proportion to $\mathrm{H}_{2}$ concentration. The WF of $\mathrm{PdH}_{x}$ moves close to a donor state of PET, and the charge transfer between the two friction surfaces can be facilitated. Triboelectric $\mathrm{H}_{2}$ sensor demonstrated reproducible and sensitive responses up to $1 \%$ $\mathrm{H}_{2}$. The approach introduced here can be easily adopted to development of triboelectric gas sensors detecting other gas species and other self-powered electronics devices.

Acknowledgments: This research was supported by Basic Science Research Program through the National Research Foundation of Korea (NRF-2015R1A1A1A05027235), the support of KIMM (Korea Institute of Machinery \& Materials) research grant (NK 196E), and the research fund of Chungnam National University 2015.

Author Contributions: Junghyo Nah conceived and designed the experiments; Yang Hyeog Kwon, Sung-Ho Shin, and Young-Hwan Kim performed the experiments; Junghyo Nah, Yang Hyeog Kwon, Joo-Yun Jung, and Young-Hwan Kim analyzed the data; Junghyo Nah, Sung-Ho Shin, and Yang Hyeog Kwon wrote the paper.

Conflicts of Interest: The authors declare no conflict of interest.

\section{Abbreviations}

The following abbreviations are used in this manuscript:

$\begin{array}{ll}\mathrm{H}_{2} & \text { Hydrogen } \\ \mathrm{Pd} & \text { Palladium } \\ \mathrm{PdH}_{x} & \text { Palladium Hydride } \\ \text { IPA } & \text { Isopropyl Alcohol } \\ \text { DI water } & \text { Deionized Water } \\ \text { ITO } & \text { Indium Tin Oxide } \\ \text { PET } & \text { Polyethylene Terephthalate } \\ \text { TEM } & \text { Transmission Electron Microscopy } \\ \text { EDS } & \text { Energy-Dispersive X-ray Spectroscopy } \\ \text { MFC } & \text { Mass Flow Control } \\ \text { WF } & \text { Work Function }\end{array}$

\section{References}

1. Jacobson, M.Z.; Colella, W.G.; Golden, D.M. Cleaning the air and improving health with hydrogen fuel-cell vehicles. Science 2005, 308, 1901-1905. [CrossRef] [PubMed]

2. Service, R.F. The hydrogen backlash. Science 2004, 305, 958-961. [CrossRef] [PubMed] 
3. Hübert, T.; Boon-Brett, L.; Black, G.; Banach, U. Hydrogen sensors-A review. Sens. Actuators B Chem. 2011, 157, 329-352. [CrossRef]

4. $\quad$ Chung, M.G.; Kim, D.-H.; Seo, D.K.; Kim, T.; Im, H.U.; Lee, H.M.; Yoo, J.-B.; Hong, S.-H.; Kang, T.J.; Kim, Y.H. Flexible hydrogen sensors using graphene with palladium nanoparticle decoration. Sens. Actuators B Chem. 2012, 169, 387-392. [CrossRef]

5. Liekhus, K.J.; Zlochower, I.A.; Cashdollar, K.L.; Djordjevic, S.M.; Loehr, C.A. Flammability of gas mixtures containing volatile organic compounds and hydrogen. J. Loss Prev. Proc. 2000, 13, 377-384. [CrossRef]

6. Wong, Y.M.; Kang, W.P.; Davidson, J.L.; Wisitsora-At, A.; Soh, K.L. A novel microelectronic gas sensor utilizing carbon nanotubes for hydrogen gas detection. Sens. Actuators B Chem. 2003, 93, 327-332. [CrossRef]

7. Shin, W.; Matsumiya, M.; Izu, N.; Murayama, N. Hydrogen-selective thermoelectric gas sensor. Sens. Actuators B Chem. 2003, 93, 304-308. [CrossRef]

8. Kaniyoor, A.; Imran Jafri, R.; Arockiadoss, T.; Ramaprabhu, S. Nanostructured Pt decorated graphene and multi walled carbon nanotube based room temperature hydrogen gas sensor. Nanoscale 2009, 1, 382-386. [CrossRef] [PubMed]

9. Han, C.-H.; Hong, D.-W.; Han, S.-D.; Gwak, J.; Singh, K.C. Catalytic combustion type hydrogen gas sensor using $\mathrm{TiO}_{2}$ and UV-LED. Sens. Actuators B Chem. 2007, 125, 224-228. [CrossRef]

10. Kiefer, T.; Salette, A.; Villanueva, L.G.; Brugger, J. Large arrays of chemo-mechanical nanoswitches for ultralow-power hydrogen sensing. J. Micromech. Microeng. 2010, 20. [CrossRef]

11. Jang, B.; Lee, K.Y.; Noh, J.-S.; Lee, W. Nanogap-based electrical hydrogen sensors fabricated from Pd-PMMA hybrid thin films. Sens. Actuators B Chem. 2014, 193, 530-535. [CrossRef]

12. Lee, J.; Shim, W.; Lee, E.; Noh, J.S.; Lee, W. Highly mobile palladium thin films on an elastomeric substrate: Nanogap-based hydrogen gas sensors. Angew. Chem. Int. Ed. 2011, 50, 5301-5305. [CrossRef] [PubMed]

13. Sil, D.; Hines, J.; Udeoyo, U.; Borguet, E. Palladium nanoparticle-based surface acoustic wave hydrogen sensor. ACS Appl. Mater. Interfaces 2015, 7, 5709-5714. [CrossRef] [PubMed]

14. Jakubik, W.P.; Urbanczyk, M.W.; Kochowski, S.; Bodzenta, J. Bilayer structure for hydrogen detection in a surface acoustic wave sensor system. Sens. Actuators B Chem. 2002, 82, 265-271. [CrossRef]

15. Kim, K.S.; Chung, G.S. Fast response hydrogen sensors based on palladium and platinum/porous 3C-SiC Schottky diodes. Sens. Actuators B Chem. 2011, 160, 1232-1236. [CrossRef]

16. Chen, H.-I.; Chou, Y.-I.; Chu, C.-Y. A novel high-sensitive Pd/InP hydrogen sensor fabricated by electroless plating. Sens. Actuators B Chem. 2002, 85, 10-18. [CrossRef]

17. Tittl, A.; Mai, P.; Taubert, R.; Dregely, D.; Liu, N.; Giessen, H. Palladium-based plasmonic perfect absorber in the visible wavelength range and its application to hydrogen sensing. Nano Lett. 2011, 11, 4366-4369. [CrossRef] [PubMed]

18. Chadwick, B.; Tann, J.; Brungs, M.; Gal, M. A hydrogen sensor-based on the optical-generation of surface-plasmons in a Palladium Alloy. Sens. Actuators B Chem. 1994, 17, 215-220. [CrossRef]

19. Gurlo, A.; Clarke, D.R. High-sensitivity hydrogen detection: Hydrogen-induced swelling of multiple cracked palladium films on compliant substrates. Angew. Chem. Int. Ed. 2011, 50, 10130-10132. [CrossRef] [PubMed]

20. Fan, F.R.; Tian, Z.Q.; Wang, Z.L. Flexible triboelectric generator! Nano Energy 2012, 1, 328-334. [CrossRef]

21. Fan, F.-R.; Lin, L.; Zhu, G.; Wu, W.; Zhang, R.; Wang, Z.L. Transparent triboelectric nanogenerators and self-powered pressure sensors based on micropatterned plastic films. Nano Lett. 2012, 12, 3109-3114. [CrossRef] [PubMed]

22. Zhu, G.; Chen, J.; Zhang, T.; Jing, Q.; Wang, Z.L. Radial-arrayed rotary electrification for high performance triboelectric generator. Nat. Commun. 2014, 5. [CrossRef] [PubMed]

23. Jeong, C.K.; Baek, K.M.; Niu, S.; Nam, T.W.; Hur, Y.H.; Park, D.Y.; Hwang, G.-T.; Byun, M.; Wang, Z.L.; Jung, Y.S.; et al. Topographically-designed triboelectric nanogenerator via block copolymer self-assembly. Nano Lett. 2014, 14, 7031-7038. [CrossRef] [PubMed]

24. Kwon, Y.H.; Shin, S.-H.; Jung, J.-Y.; Nah, J. Scalable and enhanced triboelectric output power generation by surface functionalized nanoimprint patterns. Nanotechnology 2016, 27. [CrossRef] [PubMed]

25. Kwon, Y.H.; Shin, S.-H.; Kim, Y.-H.; Jung, J.-Y.; Lee, M.H.; Nah, J. Triboelectric contact surface charge modulation and piezoelectric charge inducement using polarized composite thin film for performance enhancement of triboelectric generators. Nano Energy 2016, 25, 225-231. [CrossRef] 
26. Shin, S.-H.; Kwon, Y.H.; Kim, Y.-H.; Jung, J.-Y.; Lee, M.H.; Nah, J. Triboelectric charging sequence induced by surface functionalization as a method to fabricate high performance triboelectric generators. ACS Nano 2015, 9, 4621-4627. [CrossRef] [PubMed]

27. Zhang, H.; Yang, Y.; Su, Y.; Chen, J.; Hu, C.; Wu, Z.; Liu, Y.; Wong, P.W.; Bando, Y.; Wang, Z.L. Triboelectric nanogenerator as self-powered active sensors for detecting liquid/gaseous water/ethanol. Nano Energy 2013, 2, 693-701. [CrossRef]

28. Uddin, A.S.M.I.; Chung, G.-S. A self-powered active hydrogen gas sensor with fast response at room temperature based on triboelectric effect. Sens. Actuators B Chem. 2016, 231, 601-608. [CrossRef]

29. Horn, R.G.; Smith, D.T. Contact electrification and adhesion between dissimilar materials. Science 1992, 256, 362-364. [CrossRef] [PubMed]

30. Harms, U.; Schwarz, R.B. Anomalous modulus and work function at the interfaces of thin films. Phys. Rev. B 2002, 2, 085409. [CrossRef]

31. Lowell, J.; Rose-Innes, A.C. Contact electrification. Adv. Phys. 1980, 29, 947-1023. [CrossRef]

32. Grattan, K.T.V. Physics, chemistry \& technology of solid state gas sensor devices. J. Mod. Opt. 1995, 42, 1553.

(C) 2016 by the authors; licensee MDPI, Basel, Switzerland. This article is an open access article distributed under the terms and conditions of the Creative Commons Attribution (CC-BY) license (http://creativecommons.org/licenses/by/4.0/). 